\title{
Studies on Ocimum basilicum mucilage based solid dispersions of indomethacin for enhancement of dissolution rate
}

\author{
Sfurti S. SAKHARE ${ }^{1,2}$ * (D), Fahim J. SAYYAD ${ }^{2}$ (D) \\ 1 Department of Pharmaceutics, Gourishankar Institute of Pharmaceutical Education and Research, Limb, Satara, India. \\ 2 Department of Pharmaceutics, Government College of Pharmacy, Karad, District Satara, Maharashtra, India. \\ * Corresponding Author. E-mail: sfurti_28@rediffmail.com (S.S.); Tel. +912164 271196.
}

Received: 10 January 2019 / Revised: 06 June 2019 / Accepted: 07 June 2019

\begin{abstract}
The main aim of this study was to enhance the dissolution rate of BCS class II drug Indomethacin (IND) by solid dispersion (SD) techniques using Ocimum basilicum mucilage (OBM) as a carrier. Solid dispersions of indomethacin were prepared by using Ocimum basilicum mucilage by four different methods. Effect of methods of preparation on dissolution rate was studied. It was found that the dissolution rate of IND from its SD was dependent on the method of preparation of solid dispersions. Dissolution study revealed that the physical mixture and kneading method were convenient and effective methods for dissolution enhancement of poorly water soluble drug IND, among various methods of preparation of SD. The prepared SD's were characterized by FTIR, Differential Scanning Calorimetry, and X-ray diffraction studies. From the study we conclude that OBM could be used as a potential carrier in enhancing the dissolution rate and ultimately bioavailability of IND.
\end{abstract}

KEYWORDS: dissolution enhancement; indomethacin; Ocimum basilicum; mucilage; solid dispersions.

\section{INTRODUCTION}

The poor solubility of new chemical entities decreases the oral bioavailability of these drugs as dissolution being the rate limiting step. Hence, enhancing of solubility and bioavailability is the major challenge faced by formulation scientist. So for enhancing the solubility many techniques have been used, like particle size reduction, crystal engineering, use of surfactants, nanoparticles etc. solid dispersion [SD] being one of them [1]. SDs can be defined as molecular mixtures of poorly water soluble drugs in hydrophilic carriers, which present a drug release profile that is driven by the polymer properties. Solid dispersion is a unique approach which was introduced by Sekiguchi and Obi. In this method, the drug is dispersed in extremely fine state in an inert water soluble carrier in solid state. Number of insoluble drugs has shown to improve their dissolution character when converted to solid dispersion. Solid dispersion technology is a wellknown process used to increase the dissolution kinetics and oral absorption of poorly water soluble drugs using water soluble inert carriers. A number of freely water soluble materials such as citric acid, succinic acid, bile acids, sterols and related compounds and polymers like polyvinyl pyrrolidone and poly ethylene glycols are used as carrier for solid dispersions. By this approach the dissolution rate and bioavaibility of poorly soluble drugs can be increased. The use of hydrophilic polymers as carriers for the dissolution rate enhancement of poorly water-soluble drug is increasing. Various hydrophilic carriers such as natural polymers have been investigated for improvement of dissolution characteristics and bioavailability of poorly aqueous soluble drugs [2]. With the increasing interest in polymers of natural origin, the pharmaceutical world has compliance to use most of them in their formulations. In recent years there has been an important development in different dosage forms for existing and newly designed drugs and natural products, and semisynthetic as well as synthetic excipients often need to be used for a variety of purposes [3].

The polymers used in formulation of solid dispersion should be able maintain the supersaturated drug concentration in vivo, the most commonly used polymers in formulation of solid dispersions are some cellulose derivatives such as hydroxypropyl methylcellulose (HPMC) and hydroxypropylmethylcellulose acetate succinate (HPMCAS) and vinyl polymers such as poly (vinylpyrrolidone) (PVP) and poly(vinylpyrrolidone-co-vinylacetate) (PVPVA). The plant based polymers have been studied for their

How to cite this article: Sakhare SS, Sayyad FJ. Studies on Ocimum basilicum mucilage based solid dispersions of indomethacin for enhancement of dissolution rate. J Res Pharm. 2019; 23(5): 832-838. 
application in different pharmaceutical dosage forms. They have been utilized as viscosity enhancers, stabilizers, disintegrants, solubilisers, emulsifiers, suspending agents, gelling agents, bioadhesives, and binders in various dosage forms. Gum and mucilages are widely used natural materials for conventional and novel dosage forms [4].

Indomethacin is a non-steroidal anti-inflammatory drug (NSAID) commonly used as a prescription medication to reduce fever, pain, stiffness, and swelling. It works by inhibiting the production of prostaglandins, molecules known to cause these symptoms. Indomethacin is a BCS class II drug according to the Biopharmaceutics Classification System. It is a poorly water soluble antirheumatic agent. In literature attempts has been mase to improve the dissolution rate of indomethacin by various techniques like supersaturable delivery systems such as amorphous self-micellizing solid dispersions (SmSDs) [5] amorphous indomethacin coating with chitosan [6] mesoporous silica nanorods [7], spray drying with silica, polyvinylpyrrolidone (PVP) or 2-hydroxypropyl- $\beta$-cyclodextrin (HP $\beta C D)[8]$ Indomethacin:tromethamine a highly crystalline salt by hot melt extrusion technology [9] melt-electrospun fibers (MSFs) [10], Solid dispersions by modified melt and quench-cooling $(\mathrm{QC})$ method with graft copolymer (Soluplus ${ }^{\circledR}$ ) or polyol sugar alcohol (xylitol)[11], microwave assisted in situ amorphization of indomethacin with PVP [12], coamorphous salts of indomethacin-lysine[13] .

Ocimum basilicum plant have been used in traditional medicine due to its medicinal properties like antibacterial, antifungal, antispasmodic, carminative, diaphoretic, digestive, emmenagogue, expectorant, stimulant, stomachic. The plant is generally used in treatments of problems concerning digestion and nervous system. In pharmaceutical formulations mucilage has been used as binder, disintegrant, as a release retardant. The mucilages may have amorphous domains and may be able to accommodate drug molecules with greater stability [14]. The objectives of present investigation were to formulate and evaluate Ocimum basilicum mucilage based solid dispersions of indomethacin by various simple techniques.

\section{RESULTS AND DISCUSSION}

\subsection{Infrared spectroscopic study}

Indomethacin and SD's of each method were subjected to FTIR spectroscopic analysis (Figure 1), to ascertain whether there is any interaction between the drug and the polymer used. The characteristic peaks of the pure drug were compared with peaks obtained from their respective formulations and are given in the table 1. The peaks obtained in the spectra's of each formulation correlates with the peaks of drug spectrum, indicating that the drug was compatible with formulation and other additives used in the formulation of solid dispersion. The FTIR pattern revealed that breakdown of the intermolecular hydrogen bond of crystalline drug had taken place with the formation of hydrogen bond between the drug and the polymer. This could be confirmed by slight shift of IR bands related to hydroxyl group to lower side indicates the hydrogen bonding $[5,9]$.

Table 1. FTIR study results.

\begin{tabular}{|c|c|c|c|c|c|c|c|}
\hline $\begin{array}{l}\text { Sr. } \\
\text { No }\end{array}$ & Type of peak & $\begin{array}{c}\text { Theoretical } \\
\text { wave } \\
\text { number } \\
\left(\mathrm{cm}^{-1}\right)\end{array}$ & $\begin{array}{c}\text { Observed } \\
\text { peak } \\
\text { (IND) } \\
\left(\mathrm{cm}^{-1}\right) \\
\end{array}$ & $\begin{array}{c}\text { Observed } \\
\text { peak } \\
\text { (IM1) } \\
\left(\mathrm{cm}^{-1}\right) \\
\end{array}$ & $\begin{array}{c}\text { Observed } \\
\text { peak } \\
\text { (IM2) } \\
\left(\mathrm{cm}^{-1}\right) \\
\end{array}$ & $\begin{array}{c}\text { Observed } \\
\text { peak } \\
(\mathrm{IM} 3) \\
\left(\mathrm{cm}^{-1}\right) \\
\end{array}$ & $\begin{array}{c}\text { Observed } \\
\text { peak } \\
(\mathrm{IM} 4) \\
\left(\mathrm{cm}^{-1}\right)\end{array}$ \\
\hline 1. & $\mathrm{C}=\mathrm{O}$ Stretch & $1715-1695$ & 1694 & 1690 & 1689 & 1690 & 1689 \\
\hline 2. & $\begin{array}{l}\text { Aromatic } \mathrm{C} \equiv \mathrm{C} \\
\text { stretching }\end{array}$ & $1600-1580$ & 1588 & - & - & - & - \\
\hline 3. & $\begin{array}{l}\mathrm{O}-\mathrm{CH}_{3} \\
\text { deformation } \\
\mathrm{C}-\mathrm{O} \text { stretch and }\end{array}$ & $1485-1465$ & 1455 & 1478 & 1478 & 1478 & 1477 \\
\hline 4. & $\begin{array}{l}\mathrm{OH} \\
\text { deformation }\end{array}$ & $1320-1210$ & 1226 & 1228 & 1227 & 1226 & 1227 \\
\hline 5. & $\begin{array}{l}\text { Carboxyl OH } \\
\text { out of plane } \\
\text { deformation }\end{array}$ & Approx 925 & 926 & 926 & 925 & 925 & 903 \\
\hline
\end{tabular}




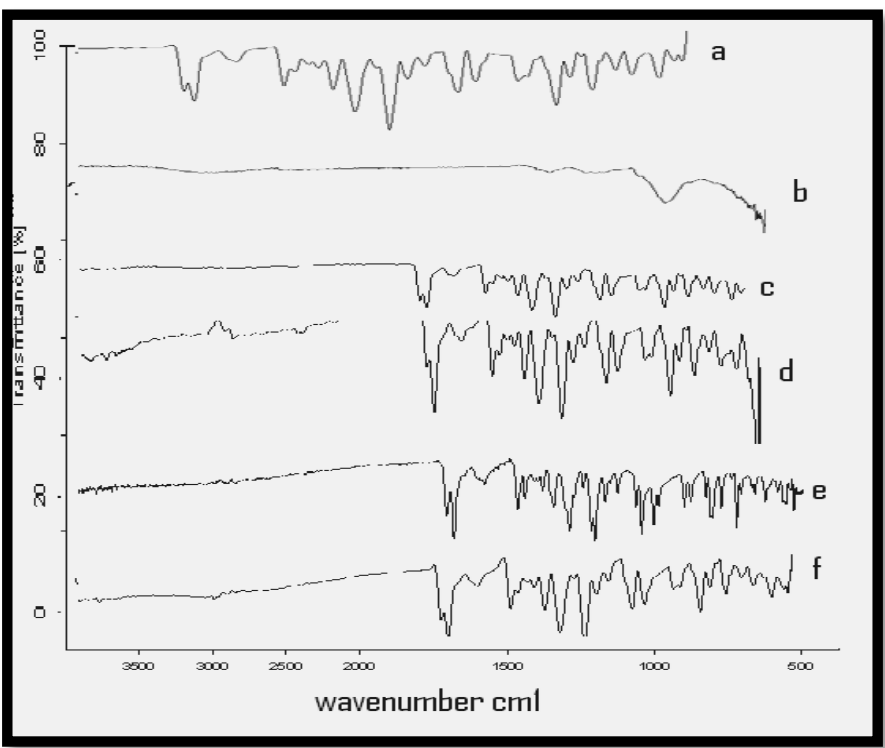

Figure 1. FTIR spectra of (a) pure indomethacin (b) Ocimum basilicum mucilage (c) IM1 (d) IM2 (e) IM3 (f) IM4.

\subsection{Differential scanning calorimetry}

Differential scanning calorimetry (DSC) was used to measure the occurrence of exothermal or endothermal changes with an increase in temperature. The DSC thermograms of IND, OBM, and solid dispersions are shown in Figure 2. Pure indomethacin has showed well defined endothermic peak $\left(\mathrm{T}_{\mathrm{m}}\right)$ at $161.03^{\circ} \mathrm{C}$ corresponding to the melting point of crystalline drug. The thermograms of OBM exhibited a broad endothermic peak at $118.6^{\circ} \mathrm{C}$ indicating decrease in crystallinity of indomethacin in prepared formulations. The DSC thermogram of SD's (IM1 to IM4) illustrated a wider endothermic peak at 85.64, 76.68, 83.55, 76.30 ${ }^{\circ} \mathrm{C}$ respectively. The shifting of melting endotherms to lower side indicates the decrease in crystallinity of indomethacin in formulated solid dispersions $[5,9]$.

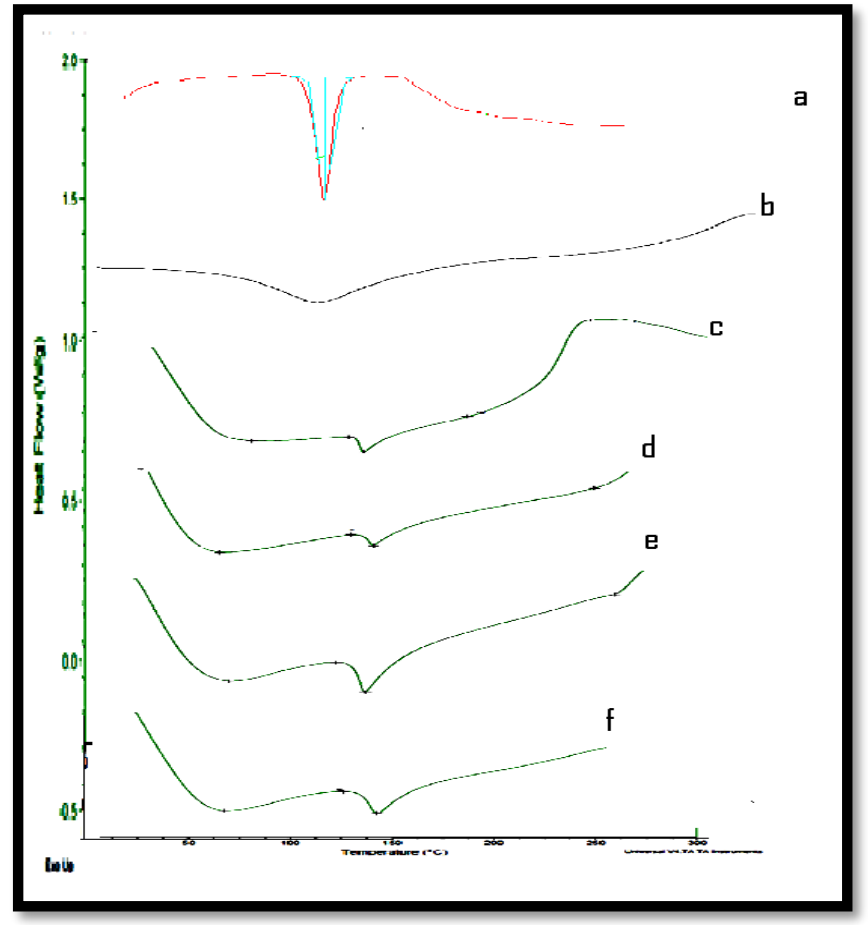

Figure 2. DSC of (a) pure drug indomethacin (b) Ocimum basilicum mucilage (c) IM1 (d) IM2 (e) IM3 (f) IM4. 


\subsection{X-Ray diffraction studies}

XRD spectra of pure IND, OBM, and solid dispersions are presented in Figure 3. The PXRD scan of plain IND showed intense peak at $11.62^{\circ}$ and $23.79^{\circ}(2 \theta)$ with peak intensity 2330,2314 respectively indicating its crystalline nature. However, all major characteristic crystalline peaks appear in the diffractogram of solid dispersions system but of low intensity indicating reduced crystallinity of drug. This may be due to partial conversion of the drug to amorphous state from crystalline state. From the PXRD study of Ocimum basilicum

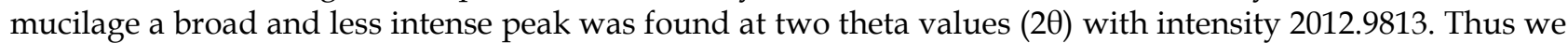
can conclude Ocimum basilicum mucilage is amorphous in nature. The sample shows only few identifiable peaks at approximately $15^{\circ}, 27^{\circ}$ and $30^{\circ} 2 \theta$. However, other peaks were very weak and unresolved or are shoulders on more intense peaks. The result of the XRD confirms with that of the DSC results.[5,9]

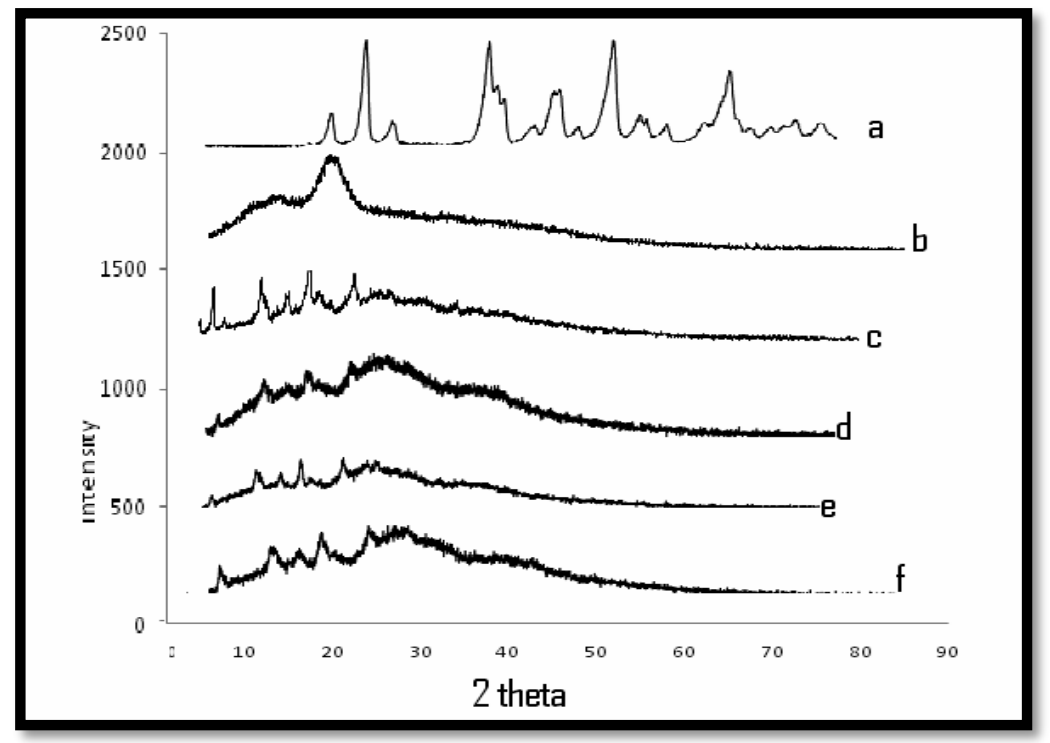

Figure 3. PXRD of (a) Pure drug indomethacin (b) Ocimum basilicum mucilage (c) IM1 (d) IM2 (e) IM3 (f) IM4.

\subsection{In vitro dissolution rate study}

In vitro dissolution test studies were carried out by varying the dissolution medias to see its effect on percentile drug release. Following table 2 gives the results of effect of dissolution media on rate of drug release from solid dispersions. The results reflected that dissolution media affects the drug release pattern variably. It was observed that dissolution rate of SD's prepared by kneading method was increased significantly as compared to original drug in phosphate buffer $\mathrm{pH} 7.2(1$ parts in phosphate buffer $\mathrm{pH} 7.2+4$ parts DW as per Indian pharmacopoeia)dissolution media. The increase in dissolution rate was found to be 4 fold greater in physical mixture while in case of co-grinding method dissolution pattern was observed 1.7 fold greater. Solvent drop method increased the dissolution rate by 2.8 fold. Kneading method was found to give better drug release as compared to other methods since the dissolution rate was increased 7.2 fold. Pure drug didn't give any drug release in distilled water whereas the solid dispersions gave significant increase in dissolution rate in distilled water. SD's prepared by kneading method gave highest drug release as compared to other methods. The increase in dissolution rate of IND SD's in distilled water may be attributed to the hydrophilic nature of OBM which might have incorporated insoluble drug moiety into hydrophilic core thus facilitating its dissolution behavior and maintaining drug in supersaturated level. The drug was found to be released and also the drug release was increased in all formulations by using phosphate buffer $\mathrm{pH}$ 6.8as dissolution media. Thus it can be concluded that even if the dissolution media was changed the pure drug release was not found to be significantly increased. SD's of IND helps in enhancing the overall solubility in various medias, dissolution studies reveals that as compared to pure drug; solid dispersions showed marked increase in dissolution rate. The improvement in dissolution rate may be due to the formation of molecular dispersion of indomethacin in Ocimum basilicum mucilage, leads to partial miscibility, improving the hydrophilic characteristics of the drug substances through interaction with the mucilage $[5,9,11]$. 
Table 2. Dissolution profile of pure drug and solid dispersions.

\begin{tabular}{lccccc}
\hline $\begin{array}{l}\text { \%Drug release (at the end of } \\
\text { 60 min) }\end{array}$ & Pure drug & IM1 & IM2 & IM3 & IM4 \\
\hline $\begin{array}{l}\text { Phosphate buffer pH 7.2(1 } \\
\text { parts+4 parts DW) as media }\end{array}$ & $5.45 \pm 0.01$ & $21.88 \pm 0.05$ & $9.3 \pm 0.04$ & $15.61 \pm 0.066$ & $39.14 \pm 0.03$ \\
$\begin{array}{l}\text { Distilled water as media } \\
\text { 0.1 N HCl as media }\end{array}$ & $10.13 \pm 0.04$ & $66.10 \pm 0.06$ & $92.31 \pm 0.013$ & $96.56 \pm 0.02$ & $98.33 \pm 0.05$ \\
$\begin{array}{l}\text { Phosphate buffer pH 6.8as } \\
\text { media }\end{array}$ & $7.32+0.05$ & $99.09 \pm 0.04$ & $43.85 \pm 0.06$ & $85.23 \pm 0.01$ & $25.34 \pm 0.02$ \\
\hline
\end{tabular}

\section{CONCLUSION}

The extracted mucilage of Ocimum basilicum has the potential as a pharmaceutical excipient.In conclusion, our studies showed that OBM could be used as a potential carrier in the dissolution rate enhancement of IND. Amongst all the methods used in the preparation of solid dispersions, physical mixing and kneading gave improved dissolution rate and required less amount of organic solvent.

\section{MATERIALS AND METHODS}

\subsection{Materials}

The Ocimum basilicum seeds were procured from the local market and Ocimum basilicum mucilage was isolated from seeds and kept in dessicator until further use. Indomethacin was obtained as gift sample from Alembic pharm. Ltd.Vadodara. All other materials used were of analytical reagent grade.

\subsection{Isolation and purification of ocimum basilicum mucilage [15]}

Ocimum basilicum seeds were procured and cleaned by washing with distilled water and then soaked in $500 \mathrm{ml}$ of distilled water with intermittent stirring for 12-14 h until soft. The soft seed material was subjected to slow stirring using overhead stirrer (Remi India) and seedless white colored mucilaginous material was collected by filtering through muslin cloth. The mucilage was collected and purified by precipitation method by using $250 \mathrm{ml}$ of $95 \%$ ethanol. Collected mucilage was dried in the oven at $50-55^{\circ} \mathrm{C}$ for $4-5 \mathrm{~h}$. Dried mucilage was scraped with spatula and powdered using pestle and mortar. Mucilage was sieved using mesh no. 60 and stored in desiccators for further studies.

\subsection{Methods of preparation of solid dispersion [16]} OBM.

Solid dispersions were prepared by different methods to enhance the aqueous solubility of IND using

\subsubsection{Physical mixture: (IM1)}

The physical mixture (PM) of IND and OBM were prepared by simple mixing the IND and OBM in $1: 1 w / w$ ratio with a spatula and passed through a 100-mesh sieve.

\subsubsection{Co-grinding method for solid dispersions: (IM2)}

Solid dispersion was prepared by using IND and OBM in 1:1w/w ratio in mortar and pestle for $10 \mathrm{~min}$ passed through a 100-mesh sieve.

\subsubsection{Solvent drop method for solid dispersions (IM3)}

Solvent drop method was used for preparing solid dispersions of IND and OBM. in this method IND and OBM in 1:1w/w ratio were mixed by adding few drops of mixture of solvent (ethanol + water) and triturated in mortar and pestle the powder was dried and stored in desiccator until use.

\subsubsection{Kneading method for solid dispersions (IM4)}

In this method, weighed quantity of drug and polymer (1:1w/w ratio) placed in a mortar and then the mixture was kneaded with 1.5 times the amount of either ethanol $70 \% v / v$ or water for $20 \mathrm{~min}$. The kneaded mixtures were dried in oven at $40^{\circ} \mathrm{C}$ until it reached uniform weight and then pulverized and screened through 100-mesh sieve. 


\subsection{Solid state characterization of solid dispersion}

\subsubsection{Infrared spectroscopic study}

Fourier transformed infrared (FTIR) spectra of IND, OBM, physical mixture, and solid dispersions of IND-OBM were obtained on a FTIR (84005 Shimadzu, Japan) using the KBr disk method (2-mg sample in $200 \mathrm{mg} \mathrm{KBr}$ ). The scanning range was 450 to $4,000 \mathrm{~cm}^{-1}$ and the resolution was $1 \mathrm{~cm}^{-1}$.

\subsubsection{Differential scanning calorimetry}

DSC curves of IND, OBM and solid dispersions were obtained by a differential scanning calorimeter (DSC 60 Shimadzu, Japan) at a heating rate of $10^{\circ} \mathrm{C} / \mathrm{min}$ from $30^{\circ} \mathrm{C}$ to $300^{\circ} \mathrm{C}$ in nitrogen atmosphere.

\subsubsection{X-ray diffraction studies}

Powder XRD patterns of IND, OBM, and solid dispersions were recorded using diffractogram (PW 1140, Mettler Toledo, and Columbus, $\mathrm{OH}, \mathrm{USA}$ ) and $\mathrm{Cu}-\mathrm{ka}$ radiation. Diffractogram were run at a scanning speed of $2^{\circ} / \mathrm{mm}$ and a chart speed of $2^{\circ} / 2 \mathrm{~cm}$ per $2 \theta$.

\subsubsection{In vitro dissolution rate study}

Dissolution rates from different solid dispersions were determined in $750 \mathrm{ml}$ of four different dissolution medias phosphate buffer $\mathrm{pH}$ 7.2(1 parts phosphate buffer $\mathrm{pH} 7.2+4$ parts DW as per Indian pharmacopoeia), distilled water, $0.1 \mathrm{~N} \mathrm{HCl}$ and phosphate buffer $\mathrm{pH} 6.8$ as media with a stirrer rotation speed of $100 \mathrm{rpm}$ using the USP dissolution test apparatus (TDT 08L - ELECTROLAB, Mumbai, India) employing a paddle (method II). A 5-ml aliquot of dissolution medium was withdrawn at 10, 20, 30, 40, 50, and 60 min with a pipette. The samples were suitably diluted and assayed spectrophotometrically at $320 \mathrm{~nm}$. Each dissolution test was carried out in triplicate. The dissolution tests were repeated by using following Medias to determine the effect of dissolution media on drug release.

Acknowledgements: The authors are thankful to the Principal, Government College of Pharmacy Karad for providing all the necessary laboratory facilities.

Author contributions: Concept - S.S.S., F.J.S.; Design -S.S.S., F.J.S.; Supervision - S.S.S., F.J.S.; Materials - S.S.S., F.J.S.; Data Collection and/or Processing - S.S.S., F.J.S.; Analysis and/or Interpretation - S.S.S., F.J.S.; Literature Search S.S.S., F.J.S.; Writing - S.S.S., F.J.S.; Critical Reviews - S.S.S., F.J.S.

Conflict of interest statement: We wish to confirm that there are no known conflicts of interest associated with this publication and there has been no significant financial support for this work that could have influenced its outcome.

\section{REFERENCES}

[1] Cid AG, Simonazzi A, Palma SD, Bermúdez JM. Solid dispersion technology as a strategy to improve the bioavailability of poorly soluble drugs. Ther Deliv. 2019; 10(16): 363-382. [CrossRef]

[2] Nair LS, Laurencin CT. Biodegradable polymers as biomaterials. Prog Polym Sci. 2007; 32(8-9): 762-798. [CrossRef]

[3] Patil PS. Natural excipients: Uses of pharmaceutical formulations. Int J Pharm Tech Res. 2014; 6: 21-28.

[4] Jani GK, Shah DP, Prajapatia VD, Jain VC. Gums and mucilages: Versatile excipients for pharmaceutical formulations. Asian J Pharm Sci. 2009; 4: 308-32.

[5] Shi NQ, Wang SR, Zhang Y, Huo JS, Wang LN, Cai JH, Li ZQ, Xiang B, Qi XR. Hot melt extrusion technology for improved dissolution, solubility and "spring-parachute" processes of amorphous self-micellizing solid dispersions containing BCS II drugs indomethacin and fenofibrate: Profiles and mechanisms. Eur J Pharm Sci. 2019; 130: 78-90. [CrossRef]

[6] Li Y, Yu J, Hu S, Chen Z, Sacchetti M, Sun CC, Yu L. Polymer nanocoating of amorphous drugs for $1 \mathrm{mproving}$ stability, dissolution, powder flow, and tabletability: the case of chitosan-coated indomethacin. Mol Pharm. 2019; 16: 1305-1311. [CrossRef]

[7] Zhang W, Zheng N, Chen L, Xie L, Cui M, Li S, Xu L. Effect of shape on mesoporous silica nanoparticles for oral delivery of indomethacin. Pharmaceutics. 2018; 11: 1-13. [CrossRef]

[8] Li Y, Rantanen J, Yang M, Bohr A. Molecular structure and impact of amorphization strategies on intrinsic dissolution of spray dried indomethacin. Eur J Pharm Sci. 2019; 129: 1-9. [CrossRef] 
[9] Bookwala M, Thipsay P, Ross S, Zhang F, Bandari S, Repka MA. Preparation of a crystalline salt of indomethacin and tromethamine by hot melt extrusion technology. Eur J Pharm Biopharm. 2018; 131: 109-119. [CrossRef]

[10] Semjonov K, Lust A, Kogermann K, Laidmäe I, Maunu SL, Hirvonen SP, Yliruusi J, Nurk G, Lust E, Heinämäki J. Melt-electrospinning as a method to improve the dissolution and physical stability of a poorly water-soluble drug. Eur J Pharm Sci. 2018; 121: 260-268. [CrossRef]

[11] Semjonov K, Salm M, Lipiäinen T, Kogermann K, Lust A, Laidmäe I, Antikainen O, Strachan CJ, Ehlers H, Yliruusi J, Heinämäki J. Interdependence of particle properties and bulk powder behavior of indomethacin in quench-cooled molten two-phase solid dispersions. Int J Pharm. 2018; 541: 188-197. [CrossRef]

[12] Doreth M, Löbmann K, Priemel P, Grohganz H, Taylor R, Holm R, Lopez de Diego H, Rades T. Influence of PVP molecular weight on the microwave assisted in situ amorphization of indomethacin. Eur J Pharm Biopharm. 2018; 122: 62-69. [CrossRef]

[13] Kasten G, Nouri K, Grohganz H, Rades T, Löbmann K. Performance comparison between crystalline and coamorphous salts of indomethacin-lysine. Int J Pharm. 2017; 533: 138-144. [CrossRef]

[14] Bhasin M. Ocimum-Taxonomy, medicinal potentialities and economic value of essential oil. J Biosphere. 2012; 1: 4850.

[15] Sayyad FJ, Sakhare SS. Isolation, characterization and evaluation of Ocimum basilicum seed mucilage for tableting performance. Indian J Pharm Sci. 2018; 80: 282-290. [CrossRef]

[16] Nikghalb LA, Singh G, Singh G, Kahkeshan KF. Solid Dispersion: Methods and polymers to increase the solubility of poorly soluble drugs. J App Pharm Sci. 2012; 2: 170-175.

This is an open access article which is publicly available on our journal's website under Institutional Repository at http://dspace.marmara.edu.tr. 